\title{
Prostate cancer: a review of active surveillance
}

\author{
This article was published in the following Dove Press journal: \\ Research and Reports in Urology \\ 16 August 2014 \\ Number of times this article has been viewed
}

\author{
Lars Lund ${ }^{1,2}$ \\ Niels Svolgaard' \\ Mads Hvid Poulsen' \\ 'Department of Urology, \\ Odense University Hospital, \\ ${ }^{2}$ Clinical Institute, Southern \\ University of Southern Denmark, \\ Odense, Denmark
}

Correspondence: Lars Lund

Department of Urology, Odense

University Hospital, Sdr Boulevard 29.

DK-5000 Odense, Denmark

$\mathrm{Tel}+455 \mathrm{I} 408982$

Fax +45 654I I726

Email lars.lund@rsyd.dk

\begin{abstract}
The objective of this paper is to review the current recommendations for active surveillance in prostate cancer from the present prospective studies. Worldwide, there are increasing numbers of men with prostate cancer. It is now accepted as standard care that a number of men with favorable-risk disease can be followed with active surveillance. In 1995, the first prospective studies were initiated to assess the feasibility of active surveillance, in which the decision to intervene was determined by prostate-specific antigen and/or histological progression. The strategy was to provide therapy individualized to the biological behavior of the cancer. Clinical trials assessing active surveillance have usually included patients younger than 70 years of age, although the guidelines have changed over time for Gleason score and prostate-specific antigen, eg, doubling time, thereby changing the indication for active treatment. The present review focuses on patient selection, prospective studies reported in the literature, and future directions.
\end{abstract}

Keywords: active surveillance, prostate cancer, prospective studies, review

\section{Introduction}

Active surveillance (AS) has become an alternative to curative therapy for prostate cancer that is unlikely to be biologically or clinically significant. AS aims to delay and/or avoid the side effects of surgery or radiation therapy in malignancies that are unlikely to cause symptoms during a patient's lifetime. ${ }^{1}$ After $2-3$ years of follow-up, about one third of patients quit AS and switch to deferred active therapy. ${ }^{2}$ The reason for this change is the repeated biopsies, often with changes in risk classification leading to definitive therapy. ${ }^{3}$ It is generally accepted that there is more or less no difference between the treatment options with regard to the effects on disease morbidity and mortality. ${ }^{4}$ Therefore, quality of life and psychological aspects may be deciding factors in the choice of treatment. Once men have chosen AS, very few switch to radical treatment for psychological reasons. The literature states the following as the main issues: 1) the consultation with doctor and treatment choice in men diagnosed with low-risk prostate cancer, 2) the effect of AS on physical domains and resulting anxiety and distress, and on quality of life in general, 3) the possible supportive and educational interventions for patients on AS. ${ }^{5}$

\section{History}

Conservative management of prostate cancer has existed for decades. Initially this was in the form of watchful waiting, where no treatment was offered until patients developed symptoms of locally advanced disease or metastatic disease. ${ }^{6}$ Watchful waiting was 
initially offered due to a lack of evidence of the effect of definitive therapy for localized prostate cancer. However, more studies have demonstrated a clear survival benefit of definitive therapy, so watchful waiting today is limited to patients with a life expectancy of 5 years or less due to comorbidity or age. ${ }^{7}$ In the 1990s, watchful waiting was supplemented with AS, which offered conservative management with the intention to treat if the cancer progressed. Over time, use of watchful waiting has decreased as the use of AS has grown. The increase in AS has been driven by the extensive use of prostate-specific antigen (PSA), ${ }^{8}$ whereby the detection of prostate cancer has gone up, especially the detection of low-grade and lowvolume cancers. ${ }^{9}$

Before embracing conservative treatment of prostate cancer in the form of AS, one important issue has to be addressed: are the existing prospective studies valid for evaluating its use for patients with localized disease? At present, there are only data available from non-mature prospective clinical trials of AS, that have a mean follow-up time of less than 10 years. However, the answers are just around the corner, since more of the AS cohorts are approaching 10 years of mean follow-up. ${ }^{10-16}$

\section{Gleason grade and its impact on AS}

Tumor grade is the histological appearance of a cancer tissue sample taken by biopsy or surgery. The dominant grading system was introduced by Dr Donald Gleason in 1966, and is based on five different patterns seen on microscopy. ${ }^{17}$ This score was proposed as a prognostic tool whereby a higher score has a worse prognosis. The introduction of PSA measurement led to a dramatic increase in the number of patients with newly diagnosed prostate cancer. ${ }^{14}$ New diagnostic tools were introduced compared with the traditional tissue samples obtained by transurethral resection or fine needle aspiration. Transrectal ultrasound-guided biopsy became the golden standard, whereby the number of biopsies taken over time has increased from 2-4 to a minimum of 12, with some even proposing 24 as standard. ${ }^{4}$

The major change in the Gleason system came in 2005 when it was updated at a consensus conference of international experts under the auspices of the International Society of Urological Pathology. ${ }^{18,19}$ The main result of this meeting was a reclassification of Gleason pattern 3 to Gleason pattern 4 . The grading of variants and subtypes of acinar adenocarcinoma of the prostate, including cancer with vacuoles, foamy gland carcinoma, ductal adenocarcinoma, pseudohyperplastic carcinoma and small cell carcinoma have also been modified. Implementation of this resulted in a near extinction of Gleason score 2-4, and a profound reduction in Gleason score $6 .{ }^{20}$ One institution, amongst several others, has reanalyzed more than 1,800 cases, with the pathologists unaware of the primary result, ${ }^{16}$ and the average Gleason score increased from 5.95 to 6.8 . In 55\% of cases, the Gleason score increased by one point or more. That led to a noticeable reduction in cancer-specific mortality $(25 \%)$ compared with the same patients original evaluation done by the first pathologists. ${ }^{21}$ The explanation was that a large proportion of low-risk patients were moved to a higher risk group, diluting this group, so to speak, making it look like this group has reduced mortality, even the low-risk group were doing better now consisting of only "real" low-risk patients. The result is that newly diagnosed patients appear to do better than patients in the older cohorts.

The introduction of a new definition of Gleason scoring also raised awareness of the tertiary patterns in the biopsies. ${ }^{22}$ Now even a small amount of a third and higher grade would be included in pathology reports of biopsies, leading to further inflation and changes regarding risk evaluation.

The significant proportion of cases upgraded when the final result after radical prostatectomy is known, might also to some extent have an influence on the preoperative result. Pathologists knowing this may be disposed to take that into consideration when dealing with borderline cases.

The significant proportion of cases upgraded when the final result after radical prostatectomy is known, might also to some extent have an influence on the preoperative result. Pathologists, knowing this, may be disposed to take that into consideration when dealing with borderline cases. This and a higher level of experience and, of course, immunehistochemical techniques has changed the results. ${ }^{23}$ Therefore, it is of great importance to be cautious when comparing the results of old studies with those of new studies when counseling patients, for example in the case of AS. In the very near future, the number of men in this situation will rise rapidly due to the large amount of men born in the late 1940s, 1950s, and 1960s. In addition the growing education and awareness of prostate cancer will further accelerate the number of patients, leading to more cancer patients with insignificant cancers needing AS.

\section{Patient selection}

The patients included in the existing prospective trials may reflect the patients who can be offered AS in the clinic. Several different regimes on which patients may be offered AS have existed, but recently patients with the following characteristic are enrolled: Gleason score $\leq 6, \mathrm{PSA} \leq 10 \mathrm{ng} / \mathrm{mL}$, stage 
T1-T2a, $\leq 2$ positive biopsies with a maximum of $50 \%$ involvement in each biopsy. ${ }^{12-15}$ Some authors have also included patients with a Gleason score of $7(3+4)$ and a PSA up to $15 \mathrm{ng} / \mathrm{mL} .^{10,11}$ The age of the patient has been an issue in some of the series, where only patients over the age of 70 years were included. ${ }^{24}$ However, this may be abandoned, given that patients younger than 70 years of age may also benefit from AS. While the elderly (over 70 years of age) may benefit from AS by not being operated since their cancer does not progress in their lifetime, younger patients, eg, in their lifetime, the younger patients (eg, those in their early 60s) may benefit from the postponement of the treatment in order to avoid complications and adverse events after surgery. ${ }^{25}$ As a consequence, age may be an issue in AS for the well-informed patient. ${ }^{26}$

\section{Follow-up}

Patient follow-up is crucial and the tools for this are: palpation of the prostate, PSA, PSA kinetics, and rebiopsy. ${ }^{24}$ The key factor is rebiopsy within one year of the primary biopsy until new diagnostic tools are available, eg, biomarkers in blood and/or urine. Meanwhile, PSA seems to be of less importance. The rebiopsy or confirmatory biopsy serves to rule out both higher-grade disease and/or higher-volume disease, both of which may have been missed at the initial biopsy. ${ }^{27}$ When the first rebiopsy is negative or unchanged from the diagnostic biopsy, the interval between the following biopsies may be prolonged from the usual 1-2 years. It is important to remember that when serial prostate biopsies are performed as part of an AS program, they have potential associated risks, ranging from minor self-limiting bleeding to hospitalization for sepsis. A recent systematic review of the complications of prostate biopsy reported acute urinary retention in $0.2 \%-1.7 \%$ of prostate biopsies and dysuria in $6 \%-25 \% .{ }^{28}$ PSA testing

Table I Guidelines from the USA and Europe

European Association of Urology ${ }^{36}$

- Stage: cTI-2a

- PSA $\leq 10 \mathrm{ng} / \mathrm{mL}$

- Biopsy Gleason score $\leq 6$ (at least ten cores)

- $\leq 2$ positive biopsies

- Minimal biopsy core involvement ( $\leq 50 \%$ cancer per biopsy)

American Urological Association ${ }^{37}$

- Does not provide a clear set of clinical tools, rather states that AS together with interstitial prostate brachytherapy, external beam radiotherapy, and radical prostatectomy are all options for treatment of the low-risk patient. The low-risk patient is defined by PSA $\leq 10 \mathrm{ng} / \mathrm{mL}$, Gleason score $\leq 6$, and clinical stage TIc or T2a

Note: Data from Heidenreich A, Bastian PJ, Bellmunt J, et al. Guidelines on prostate cancer, updated March 2013. Available from: http://www.uroweb.org. ${ }^{36}$

Abbreviations: AS, active surveillance; PSA, prostate-specific antigen. has been an important part of the AS trials, often with PSA testing every 3 months in the first 2 years, and every 6 months hereafter, where PSA doubling times of less than 2-4 years or a yearly rise of $2 \mathrm{ng} / \mathrm{mL}$ were regarded as a trigger for curative treatment (Table 1). However, recent studies have questioned the ability of PSA kinetics to predict progression. ${ }^{29,30}$ Although PSA kinetics have been associated with a worse prognosis in other settings, this may not apply directly to patients with low-risk prostate cancer who are treated with AS. ${ }^{31,32}$ The same applies for PCA3, which appears to be useful for detection of cancer, but less useful for differentiation between low-risk, intermediate-risk, and high-risk disease. ${ }^{33}$

\section{Shift to definitive therapy}

The trigger for intervention is primarily a change from low-risk to intermediate-risk or high-risk disease, either by Gleason score, PSA, or stage. In concordance with the majority of the protocols, the presence of Gleason pattern 4 or 5 will trigger a change from AS to curative treatment, although some protocols accept patients with Gleason score $7(3+4)$ to stay on AS. ${ }^{10-16}$ A change on prostate palpation to a stage above T2a triggers curative treatment. A PSA change, with a doubling time of less than 2-4 years or an increase above $2 \mathrm{ng} / \mathrm{mL}$ in one year may trigger a change in treatment strategy; however, the data are diverse. ${ }^{10-16}$ Patient's request, mainly based on anxiety, may also play a role, and has been recorded to do so in up to $9 \%$ of patients treated with AS..$^{5,24}$

\section{Prospective studies}

There is a need for randomized prospective studies to demonstrate satisfactory outcomes of AS in selected men with localized prostate cancer. A systematic search of PubMed and Embase revealed six prospective studies and one randomized study (Table 2), totaling 4,820 patients with a median follow-up of 4.5 (range 1.9-7.4) years.

The largest study is PRIAS (Prostate Cancer Research International Active Surveillance), which included 2,499 patients and was last updated in $2012 .{ }^{10}$ It is important to mention that the PRIAS study is entirely web-based. The website (http://www.prias-project.org) offers patients information on the study and after log-in it can be used by physicians to include patient and follow-up data. As part of the inclusion criteria for PRIAS, an attempt is made to select men with insignificant organ-confined disease who have a good prognosis. The timetable for this web-based study consists of PSA measurements every 3 months and annual clinical examination during the first 2 years with annual PSA measurements and annual clinical examinations 
Table 2 Prospective studies of active surveillance in prostate cancer

\begin{tabular}{|c|c|c|c|c|c|c|c|c|}
\hline & $\begin{array}{l}\text { PRIAS } \\
2013^{10}\end{array}$ & $\begin{array}{l}\text { Dall'Era } \\
\text { et } \mathbf{a l}^{2}\end{array}$ & $\begin{array}{l}\text { Tosoian } \\
\text { et } \text { al }^{13}\end{array}$ & $\begin{array}{l}\text { Thomsen } \\
\text { et } \mathrm{al}^{24}\end{array}$ & $\begin{array}{l}\text { Klotz } \\
\text { et } \mathrm{al}^{14}\end{array}$ & $\begin{array}{l}\text { SAMS* } \\
2013^{16}\end{array}$ & $\begin{array}{l}\text { Selvadurai } \\
\text { et al" }\end{array}$ & Total \\
\hline Patients (n) & 2,494 & 321 & 769 & 167 & 450 & 148 & 471 & 4,820 \\
\hline Median follow-up (years) & 1.6 & 3.6 & 2.7 & 3.4 & 6.8 & NA & 5.7 & \\
\hline Freedom from treatment & $\begin{array}{l}77 \% \text { at } \\
2 \text { years }\end{array}$ & $\begin{array}{l}67 \% \text { at } \\
5 \text { years }\end{array}$ & $\begin{array}{l}59 \% \text { at } \\
5 \text { years }\end{array}$ & NA & $\begin{array}{l}70 \% \text { at } \\
5 \text { years }\end{array}$ & NA & $\begin{array}{l}70 \% \text { at } \\
5 \text { years }\end{array}$ & \\
\hline Prostate cancer death & 0 & 0 & 0 & 0 & $\begin{array}{l}3 \% \text { at } \\
15 \text { years }\end{array}$ & NA & $0.4 \%$ & \\
\hline
\end{tabular}

Note: *Prospective and randomized.

Abbreviation: NA, not available; PRIAS, Prostate Cancer Research International Active Surveillance; SAMS, Study of Active Monitoring in Sweden.

in subsequent years. Repeat biopsies are standard, and are planned after one, 4, 7, and 10 years of surveillance. There are strict follow-up criteria in order to follow the study. When performing a biopsy in patients the authors advise and give guidelines for the possible number of biopsies necessary depending on the prostate volume. These men were followed for a median of 1.6 years. One or more repeated biopsies were performed in 1,480 men, of whom 415 (28\%) were reclassified. These reclassifications can trigger intervention and/or discontinuing AS. The PRIAS study showed that the strongest predictors for reclassification or switching to deferred treatment were number of positive cores and PSA density. They found that the disease-specific survival rate was $100 \%$, and concluded on the basis of their short-term data that AS is a feasible strategy to reduce overtreatment.

A single-center, prospective cohort study from the Royal Marsden Hospital, UK, included men aged 50-80 years with stage T1/T2 disease, PSA $<15 \mathrm{ng} / \mathrm{mL}$, Gleason score $\leq 3+3$, and percent positive biopsy cores $\leq 50 \% .{ }^{11}$ Patients were assessed clinically and with PSA at 3-monthly intervals in year 1, at 4-monthly intervals in year 2, and at 6-monthly intervals thereafter. Transrectal ultrasound-guided prostate biopsy was performed after 18-24 months and every 2 years thereafter. The study enrolled 471 eligible patients from 2002 to 2011. Their median age was 66 years and the median initial PSA value was $6.4 \mathrm{ng} / \mathrm{mL}$. Eighty-eight percent of patients had T1 disease and $93 \%$ had a Gleason score of $\leq 3+3$. At median follow-up of 5.7 years, the 5-year rate of adverse histology and treatment-free probability was $22 \%(95 \%$ confidence interval 16-29) and 70\% (95\% confidence interval 65-75), respectively. There were two deaths from prostate cancer. The authors concluded that longer follow-up is needed to confirm the safety of this strategy.

A study from California included 321 men with PSA $<10 \mathrm{ng} / \mathrm{mL}$, biopsy Gleason sum $\leq 6$, cancer involvement in $<33 \%$ of biopsy cores, and clinical stage T1/T2a disease. ${ }^{12}$ Patients were followed with
PSA measurements and digital rectal examination every 3-6 months and with transrectal ultrasound at 6-monthly to 12 -monthly intervals. Beginning in 2003, patients also underwent repeat prostate biopsy at 12 to 24 months. The overall median follow-up was 3.6 (range 1-17) years. The initial mean PSA level was $6.5 \pm 3.9 \mathrm{ng} / \mathrm{mL}$. One hundred and twenty men (37\%) met at least one criterion for progression. Seventy-eight men (24\%) received secondary treatment at a median 3 (range 1-17) years after diagnosis. Approximately $13 \%$ of patients with no disease progression elected for treatment.

A cohort of 769 men has been followed since 1995 at John Hopkins Hospital, Baltimore, MD, USA, for a median of 2.7 (range 0.01-15.0) years. ${ }^{13}$ Enrolment criteria were T1c, PSA density $<0.15 \mathrm{ng} / \mathrm{mL}$, and prostate biopsy findings of Gleason score $\leq 6$, two or fewer cores with cancer, and $\leq 50 \%$ cancer involvement of any core. Median survival free of intervention was 6.5 (range 0.0-15.0) years after diagnosis, and the proportions of men remaining free of intervention after 2, 5, and 10 years of follow-up were $81 \%, 59 \%$, and $41 \%$, respectively. Overall, 255 men $(33.2 \%)$ underwent intervention at a median of 2.2 (range $0.6-10.2$ ) years after diagnosis, with 188 (73.7\%) undergoing intervention on the basis of disease reclassification on biopsy. The proportions of men who underwent curative intervention $(P=0.026)$ or had biopsy reclassification $(P<0.001)$ were significantly lower in men who met the enrolment criteria than in those who did not.

A group from Toronto assessed the outcome of a watchful-waiting protocol in 450 men. ${ }^{14}$ Intervention was offered to patients with a PSA doubling time of less than 3 years, Gleason score progression (to $4+3$ or greater), or unequivocal clinical progression. ${ }^{14}$ The median follow-up was 6.8 (range 1-13) years. Overall survival was $78.6 \%$, and the 10 -year prostate cancer actuarial survival was $97.2 \%$. Overall, $30 \%$ of patients have been reclassified as higher risk and have been offered definitive therapy. Of 117 patients treated 
radically, the PSA failure rate was 50\%, representing $13 \%$ of the total cohort. A PSA doubling time of 3 years or less was associated with an 8.5 times higher risk of biochemical failure after definitive treatment compared with a doubling time of more than 3 years $(P<0.0001)$.

A Danish study of 167 patients had a median follow-up of 3.4 (range 1.1-9.5) years. ${ }^{15}$ At entry, the median age was 65 (range 51-73) years, 94\% had a Gleason score $\leq 6$, $87.4 \%$ had a PSA $\leq 10 \mathrm{ng} / \mathrm{mL}$ and $99 \%$ had $\leq \mathrm{cT} 2 \mathrm{a}$ disease. Ten patients progressed on digital rectal examination, 40 patients progressed on the basis of a short PSA doubling time, and 34 patients progressed on rebiopsy. A total of 59 patients discontinued AS. The estimated 5-year probability of remaining on AS was $60.0 \%$ (95\% confidence interval 50.9-69.1).

A randomized study from Sweden, known as SAMS (Study of Active Monitoring in Sweden) is comparing two different follow-up schedules of AS for low-risk prostate cancer. ${ }^{16}$ They plan to include 500 patients over 5 years and all patients will be followed for 10-15 years. The study consists of a randomized part comparing standard rebiopsy and follow-up with an extensive initial rebiopsy coupled with less intensive follow-up and no further scheduled biopsies (SAMS-FU). Thus far, 148 patients from 13 Swedish urology centers has been included, of whom 48 are on SAMS-FU. The results of this study will contribute to fewer patients with indolent, low-risk prostate cancer receiving unnecessary treatment and more patients on AS who need treatment receiving it when the disease is still curable. The less intensive investigational follow-up in the SAMS-FU trial would reduce the health care resources allocated to this large group of patients if it replaces the present standard schedule.

A recent systematic review showed that AS patients were managed and followed by a combination of repeated biopsies, serial PSA measurements, and clinical examinations. ${ }^{24}$ The authors reported that the estimated average 5-year and 10-year probabilities of discontinuing AS were 33\% (14\%-41\%) and $55 \%(40 \%-59 \%)$, respectively. They concluded that, after discontinuing AS, the majority underwent delayed curative treatment, with an even distribution between radical prostatectomy and external radiotherapy. Only $20 \%$ of patients received hormonal therapy.

The age of the patient is a very important issue when following prostate cancer by AS. It is evident when followed in a prospective study, and therefore it should be well-defined when patients are going from active surveillance to watchful waiting. A recent systematic review of novel tools for improving patient selection and monitoring low-risk prostate cancer by AS revealed that imaging and serum markers may improve future patient selection and follow-up during AS. ${ }^{34}$ They concluded that it is necessary for prospective studies to further evaluate the clinical utility of these markers with respect to long-term outcomes of AS. They identified 787 studies of AS and included 30 in their review. ${ }^{34}$ The majority of studies $(n=14)$ included magnetic resonance imaging, five included serum markers, five included urinary markers, four histopathology markers, and two included germline genetic markers. They found that magnetic resonance imaging has a high specificity for low-risk prostate cancer and new serum markers are associated with unfavorable disease.

\section{Conclusion}

Hopefully, these prospective studies will be able to reduce overtreatment of patients with low-risk prostate cancer and selected patients with intermediate-risk disease without compromising survival. The challenges in AS include classification in order to risk stratify adequately, responsiveness in order to detect changes when they occur, and harm reduction by reducing the number and burden of repeated biopsies. It is well known that the limitations of the current AS approach include the fact that systematic biopsy does not exclude significant cancer. Some patients experience sepsis and voiding problems after biopsy, although a recent large serial study concluded that repeated biopsies do not appear to independently increase the risk of lower urinary tract symptoms in an AS population. ${ }^{35}$ There are several goals in the future of AS. Screening will probably be by blood/urinary biomarkers, imaging or be risk factor-based, thereby avoiding a diagnosis of cancer in low-risk patients. The goal for number needed to treat is one patient. Today the number needed to treat is around 100 in a low-risk group, 48 in a screening population, and 20 in a clinical population. We know that less than $6 \%$ of patients older than 65 years die from prostate cancer if not treated with radical prostatectomy or radiotherapy or if their Gleason score is $<7$. The studies show that the majority of patients discontinue AS within the first 3 years, mainly due to progression on rebiopsy and/or PSA kinetics. AS seems to be useful for the well informed patient with lowrisk disease, PSA $<10 \mathrm{ng} / \mathrm{mL}$, Gleason score $\leq 6$, T1-T2a stage disease, $\leq 2$ positive biopsies, and a maximum of $50 \%$ involvement in each biopsy. Follow-up includes repeated PSA and prostate palpation quarterly for 2 years and twice a year thereafter. Follow-up biopsy within one year, and thereafter every second year. The trigger for intervention is primarily a change from low-risk to intermediate-risk or high-risk disease by Gleason score, PSA, or stage. 


\section{Disclosure}

The authors report no conflicts of interest in this work.

\section{References}

1. Krakowsky Y, Loblaw A, Klotz L. Prostate cancer death of men treated with initial active surveillance: clinical and biochemical characteristics. J Urol. 2010;184:131-135.

2. Dall'Era MA, Albertsen PC, Bangma C, et al. Active surveillance for prostate cancer: a systematic review of the literature. Eur Urol. 2012;62:976-983.

3. Bul M, Zhu X, Valdagni R, et al. Active surveillance for low-risk prostate cancer worldwide: the PRIAS study. Eur Urol. 2013;63:597-603.

4. Heidenreich A, Bastian PJ, Bellmunt J, et al. EAU guidelines on prostate cancer. Part 1: screening, diagnosis, and local treatment with curative intent-update 2013. Eur Urol. 2014;65:124-137.

5. Van den Bergh RC, Korfage IJ, Bangma CH. Psychological aspects of active surveillance. Curr Opin Urol. 2012;22:237-242.

6. Bill-Axelson A, Holmberg L, Filén F, et al. Radical prostatectomy versus watchful waiting in localized prostate cancer: the Scandinavian Prostate Cancer Group-4 randomized trial. J Natl Cancer Inst. 2008;100:1144-1154.

7. Klotz L. Active surveillance for prostate cancer: overview and update. Curr Treat Options Oncol. 2013;14:97-108.

8. Singer EA, Kaushal A, Turkbey B, Couvillon A, Pinto PA, Parnes HL. Active surveillance for prostate cancer: past, present and future. Curr Opin Oncol. 2012;24:243-250.

9. Boevee SJ, Venderbos LD, Tammela TL, et al. Change of tumour characteristics and treatment over time in both arms of the European Randomized study of Screening for Prostate Cancer. Eur J Cancer. 2010;46:3082-3089.

10. Bul M, Zhu X, Rannikko A, et al. Radical prostatectomy for low-risk prostate cancer following initial active surveillance: results from a prospective observational study. Eur Urol. 2012;62:195-200.

11. Selvadurai ED, Singhera M, Thomas K, et al. Medium-term outcomes of active surveillance for localised prostate cancer. Eur Urol. 2013;64: 981-987.

12. Dall'Era MA, Konety BR, Cowan JE, et al. Active surveillance for the management of prostate cancer in a contemporary cohort. Cancer. 2008;112:2664-2670.

13. Tosoian JJ, Trock BJ, Landis P, et al. Active surveillance program for prostate cancer: an update of the Johns Hopkins experience. $J$ Clin Oncol. 2011;29:2185-2190.

14. Klotz L, Zhang L, Lam A, Nam R, Mamedov A, Loblaw A. Clinical results of long-term follow-up of a large, active surveillance cohort with localized prostate cancer. J Clin Oncol. 2010;28:126-131.

15. Thomsen FB, Røder MA, Hvarness H, Iversen P, Brasso K. Active surveillance can reduce overtreatment in patients with low-risk prostate cancer. Dan Med J. 2013;60:A4575.

16. Bratt Ol, Carlsson S, Holmberg E, et al. The Study of Active Monitoring in Sweden (SAMS): a randomized study comparing two different follow-up schedules for active surveillance of low-risk prostate cancer. Scand J Urol. 2013;47:347-355.

17. Gleason DF. Classification of prostatic carcinomas. Cancer Chemother Rep. 1966;50:125-128.

18. Thompson IM, Canby-Hagino E, Lucia MS. Stage migration and grade inflation in prostate cancer: Will Rogers meets Garrison Keillor. J Natl Cancer Inst. 2005;97:1236-1237.

Research and Reports in Urology

\section{Publish your work in this journal}

Research and Reports in Urology is an international, peer-reviewed, open access journal publishing original research, reports, editorials, reviews and commentaries on all aspects of adult and pediatric urology in the clinic and laboratory including the following topics: Pathology, pathophysiology of urological disease; Investigation and treatment of
19. Epstein JI, Allsbrook WC Jr, Amin MB, Egevad LL; ISUP Grading Committee. The 2005 International Society of Urological Pathology (ISUP) Consensus Conference on Gleason Grading of Prostatic Carcinoma. Am J Surg Pathol. 2005;29:1228-1242.

20. Epstein JI. An update of the Gleason grading system. J Urol. 2010;183: 433-440.

21. Albertsen PC, Hanley JA, Barrows GH, et al. Prostate cancer and the Will Rogers phenomenon. J Natl Cancer Inst. 2005;97:1248-1253.

22. Stamey TA, McNeal JE, Yemoto CM, et al. Biological determinants of cancer progression in men with prostate cancer. JAMA. 1999;281: 1395-1400.

23. Epstein JI. Pathologists should retain their individuality. Am J Surg Pathol. 2000;24:1443-1434.

24. Thomsen FB, Brasso K, Klotz LH, Røder MA, Berg KD, Iversen P. Active surveillance for clinically localized prostate cancer-a systematic review. J Surg Oncol. 2014;109:830-835.

25. Wilt TJ, Brawer MK, Jones KM, et al. Radical prostatectomy versus observation for localized prostate cancer. $N$ Engl J Med. 2012;367:203-213.

26. Klotz L. Active surveillance: patient selection. Curr Opin Urol. 2013;23:239-244

27. Adamy A, Yee DS, Matsushita K, et al. Role of prostate specific antigen and immediate confirmatory biopsy in predicting progression during active surveillance for low risk prostate cancer. $J$ Urol. 2011;185:477-482.

28. Loeb S, Vellekoop A, Ahmed HU, et al. Systematic review of complications of prostate biopsy. Eur Urol. 2013;64:876-892.

29. Ross AE, Loeb S, Landis P, et al. Prostate-specific antigen kinetics during follow-up are an unreliable trigger for intervention in a prostate cancer surveillance program. J Clin Oncol. 2010;28:2810-2816.

30. Whitson JM, Porten SP, Hilton JF, et al. The relationship between prostate specific antigen change and biopsy progression in patients on active surveillance for prostate cancer. J Urol. 2011;185:1656-1660.

31. Bangma CH, Bul M, van der Kwast TH, et al. Active surveillance for low-risk prostate cancer. Crit Rev Oncol Hematol. 2013;85:295-302.

32. Vickers AJ, Savage C, O'Brien MF, Lilja H. Systematic review of pretreatment prostate-specific antigen velocity and doubling time as predictors for prostate cancer. J Clin Oncol. 2009;27:398-403.

33. Filella X, Foj L, Milà M, Augé JM, Molina R, Jiménez W. PCA3 in the detection and management of early prostate cancer. Tumour Biol. 2013;34:1337-1347.

34. van den Bergh RC, Ahmed HU, Bangma CH, Cooperberg MR, Villers A, Parker CC. Novel tools to improve patient selection and monitoring on active surveillance for low-risk prostate cancer: a systematic review. Eur Urol. 2014;65:1023-1031.

35. Glass AS, Hilton JF, Cowan JE, Washington SL, Carroll PR. Serial prostate biopsy and risk of lower urinary tract symptoms: results from a large single-institution active surveillance cohort. Urology. 2014;83:33-38.

36. Heidenreich A, Bastian PJ, Bellmunt J, et al. Guidelines on prostate cancer, updated Mar 2013. Available from: http://www.uroweb.org. Accessed March 16, 2014.

37. Thompson I, Brantley JT, Aus G, et al. Prostate cancer, guideline for the management of clinically localized prostate cancer. Available from: http://www.auanet.org. Accessed March 16, 2014.

\section{Dovepress}

urological disease; Pharmacology of drugs used for the treatment of urological disease. The manuscript management system is completely online and includes a very quick and fair peer-review system, which is all easy to use. Visit http://www.dovepress.com/testimonials.php to read real quotes from published authors. 